\title{
PEMBUATAN WEBSITE PORTAL EKONOMI DAN WISATA (EKOWISATA) DI PULAU MAITARA KOTA TIDORE KEPULAUAN
}

\author{
Amal Khairan ${ }^{1}$, Salkin Lutfi ${ }^{2}$ \\ 1,2Program Studi Teknik Informatika, Fakultas Teknik, Universitas Khairun \\ Jl. Jati Metro, Kota Ternate Selatan \\ Email : ${ }^{1}$ ibntawakkal@gmail.com, ${ }^{2}$ salkin.lutfi@unkhair.ac.id
}

(Naskah masuk: 26 Februari 2020, diterima untuk diterbitkan: 11 Maret 2020)

\begin{abstract}
Abstrak
Pulau Maitara memiliki berbagai macam potensi wisata yang dapat dilakukan pengembangan sebagai kawasan ekowisata, dan potensi-potensi tersebut diantara panorama alam, wisata sejarah budaya, atraksi wisata, potensi fisik wisata yang relatif masih alami, tingkat aksesibilitas serta taman laut Pulau Maitara. Potensi-potensi tersebut belum didukung sepenuhnya ketersediaan sarana dan prasarana pariwisata yang memadai untuk pengembangan wisata Pulau Maitara itu sendiri, Salah satu sarana yaitu sarana promosi masih menggunakan cara konvensional yaitu menggunakan surat kabar lokal sehingga informasi ekowisata belum berskala global sehingga perlunya pembuatan website ekowisata sebagai media informasi yang dapat menjangkau wisatawan hingga mancanegara, dalam perancangan website ekowisata menggunakan metode pengembangan perangkat lunak waterfall metode ini terdapat 5 tahap pengembangan yaitu Requirement, Implementation, Verification dan Maintanance, penelitian ini menghasilkan sebuah website portal yang telah dipublikasikan dan dapat diakses secara online melalui alamat http://visit-maitaraisland.com, aplikasi website portal ekowisata pulau maitara terdapat fitur peta (map) yang memanfaatkan API google yang bertujuan sebagai penunjuk arah bagi para wisatawan yang berasal dari luar daerah, selain itu website portal ini juga memiliki fitur konten viewer yang befungsi dalam memantau konten website yang popular serta diminati oleh pengunjung website. Sistem ini telah diuji dengan black box testing $(B B T)$, dan hasil pengujian sistem berjalan sesuai dengan fungsinya.
\end{abstract}

Kata kunci : website portal, ekowisata, tidore kepulauan, visit maitara, BBT

\section{MAKING WEBSITE ECONOMIC AND TOURISM (EKOWISATA) IN THE MAITARA ISLAND OF CITY OF TIDORE ISLANDS}

\begin{abstract}
Maitara Island has a variety of tourism potentials that can be developed as ecotourism areas, and these potentials include natural panoramas, cultural historical tourism, tourist attractions, relatively unspoiled physical tourism potential, accessibility levels and marine parks of Maitara Island. These potentials have not been fully supported by the availability of adequate tourism facilities and infrastructure for the development of Maitara Island tourism itself. One of the means of promotion is that it still uses the conventional way of using local newspapers so that ecotourism information is not yet on a global scale so the need to create an ecotourism website as a media information that can reach tourists to foreign countries, in designing ecotourism websites using the waterfall software development method there are 5 stages of development, namely Requirement, Implementation, Verification and Maintenance, this research produces a portal website that has been published and can be accessed online through the http address : I/visitmaitaraisland.com, the website application of the Maitara Island ecotourism portal features a map (map) that utilizes the Google API which aims as a direction for tourists coming from outside the region, in addition to This website portal also has a content viewer feature that functions to monitor popular website content and is in demand by website visitors. This system has testing using black box testing (BBT), and result testing show system is not wrong.
\end{abstract}

Keywords : portal website, ecotourism, tidore islands, visit maitara, BBT 


\section{PENDAHULUAN}

Pulau Maitara merupakan salah satu kawasan wisata kota Tidore kepulauan, berdasarkan data statistik tahun 2017 pulau Maitara memiliki jumlah penduduk 391 jiwa dengan luas wilayah $044 \mathrm{Km} 2$ [1]. Pulau Maitara memiliki berbagai macam potensi wisata yang dapat dilakukan pengembangan sebagai kawasan ekowisata, dan potensi-potensi tersebut diantara ; panorama alam, wisata sejarah budaya, atraksi wisata, potensi fisik wisata yang relatif masih alami, tingkat aksesibilitas serta taman laut Pulau Maitara. Sumber pendapatan masyarakat pulau Maitara beragam yaitu sebagai nelayan, peternak, petani, pariwisata dan lainnya. Sebagai salah satu kawasan wisata di Kecamatan Tidore Utara, Pulau Maitara berpotensi dimanfaatkan sebagai pengembangan kawasan ekowisata yang dapat mengimbangi dampak yang terjadi akibat dari perencanaan pariwisata konvensional dengan tatanan budaya pada wilayah Maluku Utara sehingga memberikan dampak yang kecil terhadap pergeseran nilai-nilai budaya, Penyimpangan dan prilaku masyarakat pada wilayah selain itu perencanaan ekowisata membuka peluang dan kesempatan serta keterlibatan dari masyarakat dalam mengembangkan kawasan tersebut, selain itu juga dalam pengembangan kawasan ekowisata di Pulau Maitara dilakukan sesuai dengan potensi dan keunggulan yang dimiliki oleh Palau maitara itu sendiri.

Potensi-potensi tersebut belum didukung sepenuhnya ketersediaan sarana dan prasarana pariwisata yang memadai untuk pengembangan wisata Pulau Maitara itu sendiri [2]. Salah satu sarana yaitu sarana promosi masih menggunakan cara konfensional yaitu menggunakan surat kabar lokal sehingga informasi ekowisata belum berskala global. Media promosi saat ini yang dapat dengan mudah diterima oleh calon wisatawan yaitu menggunakan internet. Berdasarkan hal tersebut maka promosi mengenai Ekowisata di Kecamatan Maitara Kepulauan dapat dioptimalkan melalui website yang dimiliki oleh Taman Nasional Bunaken. Pembaharuan mengenai segala informasi dan desain layout dari website juga harus dilakukan agar menarik calon wisatawan [3]. Pengelola ekowisata bekerja sama dengan pengurus asosiasi homestay Raja Ampat dalam memasarkan homestay maupun paket perjalanan yang diiklankan melalui website [4], Untuk memudahkan pencarian lokasi ekowisata, pihak dinas pariwisata membutuhkan aplikasi berbasis web. Dengan menggunakan Google API dapat memudahkan dalam penerapan Sistem Informasi Geografis [5].

Pembuatan web GIS pernah dibuat oleh [6],[7] yang mana hasil implementasi sistem berjalan sesuai. Berdasarkan informasi dan rekomendasi dari penelitian sebelumnya ini maka perlu kiranya dilakukan penelitian untuk membuat website portal ekowisata pulau Maitara dengan memanfaatkan google map API (Aplication Programming Interface), serta penyajian statistik konten website yang disajikan sehingga diharapkan dapat mempublikasikan potensi wisata maupun kuliner yang ada dipulau Maitara untuk masyarakat sekitar pulau Maitara serta para wisatawan local dan mancanegara yang berkunjung maupun mencari informasi melalui internet, olehnya itu dilakukan penelitian dengan "Pembuatan Website Portal Ekonomi Dan Wisata (Ekowisata) Di Pulau Maitara Kota Tidore Kepulauan". Dengan Teknik pengujian black box testing. Pengujian dengan black box testing pernah juga dilakukan oleh [8]. Sedangkan tahapan perancangan aplikasi menggunakan waterfall. Sebagaimana juga diterapkan oleh [9].

\section{METODE PENELITIAN}

Tahapan-tahapan perancangan aplikasi website portal yang Penulis gunakan yaitu metode waterfall yang digambarkan sebagai berikut :

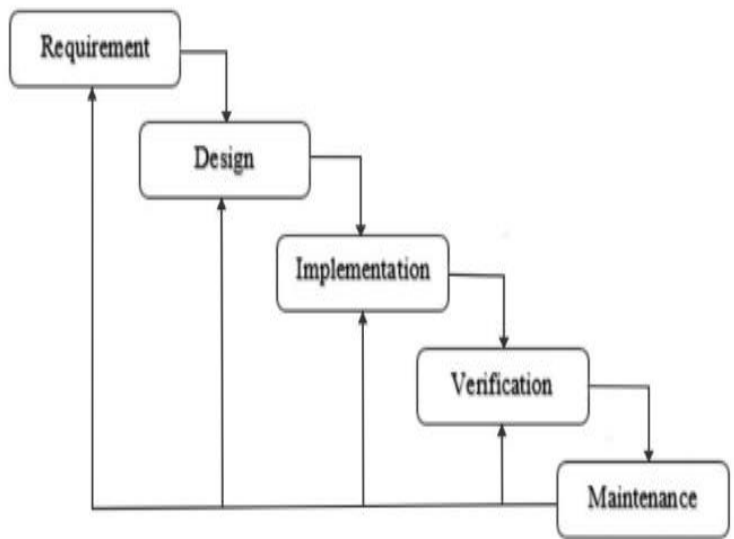

Gambar 1. metode waterfall [10]

1. Requirement

Tahapan pertama dalam perancangan website ini yaitu Penulis melakukan wawancara kepada pihakpihak yang terkait serta melakukan analisis untuk merumuskan spesifikasi sistem yang nantinya akan dirancang

2. Design

Tahapan kedua setelah mendapatkan rumusan system website yang akan dibuat, maka tahap kedua ini Penulis melakukan perancangan desain interface maupun database untuk website ini

3. Implementation

Tahap ketiga dalam merancang website ini yaitu melakukan implentasi dan menguji website yang telah dibuat apakah telah sesuai dengan spesifikasi yang telah tetapkan sebelumnya

4. Verification

Tahapan verifkasi yang Penulis lakukan adalah melakukan wawancara kepada pihak terkait pasca 
implementasi website untuk memastikan website yang direncang telah sesuai dengan spesifikasinya

\section{Maintanance}

Tahapan terakhir yang dilakukan dalam perancangan website ini yaitu melakukan perbaikan terhadap tahapan-tahapan website yang bermasalah atau tidak sesuai spesifikasi website.

\section{HASIL DAN PEMBAHASAN}

\section{A. Requirement Sistem}

Requirement sistem merupakan tahapan awal dalam perancangan aplikasi dengan menggunakan metode waterfall, pada tahap ini Penulis melakukan pengumpulan data dengan 3 metode yaitu :

1. Wawancara

Dalam metode wawancara Penulis melakukan wawancara terhadap pihak terkait agar dalam perancangan aplikasi nantinya sesuai dengan keinginan dari pihak-pihak yang terkait dengan website porta ekowisata pulau Maitara

\section{Observasi}

Pada metode observasi, Penulis melakukan pengamatan terhadap website-website ekowisata yang ada di internet sebagai framework dalam perancangan aplikasi website portal ekowisata pulau Maitara

3. Studi pustaka

Dalam studi pustaka Penulis melakukan review jurnal-jurnal ilmiah terkait ekowisata dan juga website portal, selain jurnal penulis juga menggunakan buku-buku bertemakan website dalam perancangan website ekowisata pulau Maitara

\section{B. Perancangan Sistem}

Terdapat 2 tahapan perancangan dalam pembuatan website portal ekowisata pulau Maitara, yaitu perancangan use case yakni merancangan fitur website portal baik untuk halaman user atau pengunjung maupun untuk halaman administrator atau admin dalam mengelola website portal ekowisata pulau Maitara,

\section{Perancangan Use Case Diagram}

Terdapat 2 use case diagram yang di rancang, yaitu diagram usecase administrator yang seperti pada gambar 2 dan usecase diagram user atau pengunjung website seperti pada gambar 3

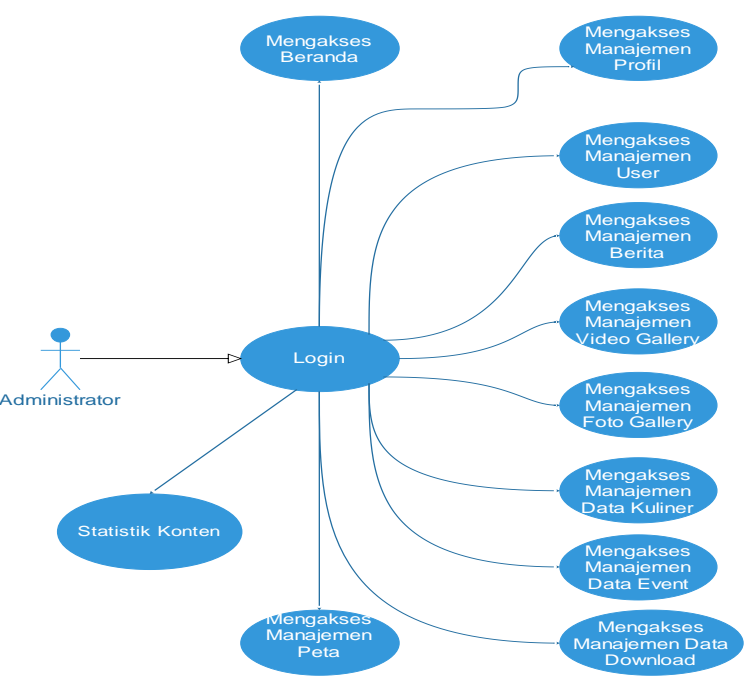

Gambar 2. use case diagram administrator

Usecase diagram yang terlihat pada gambar 2 merupakan gambaran peran dari seorang administrator dalam website ekowisata pulau Maitara, dimana seorang administrator dapat mengakses fasilitas website berikut :

1. Beranda

Halaman ini berisi informasi selamat datang dalam aplikasi ketika administrator berhasil melakukan login ke backend website portal

2. Manajemen profil

Halaman ini berisi layanan untuk seorang administrator dalam menampilkan, menambah, mengedit mapun menghapus informasi profil pulau Maitara

3. Manajemen user

Halaman ini berisi layanan website untuk seorang administrator website untuk menambah, mengubah maupun memblokir pengguna-pengguna dari website portal

4. Manajemen berita

Layanan ini berisi informasi berita dalam website portal, layanan ini untuk administrator dalam mengelolah informasi berita dalam website portal, yaitu menampilkan, menambah, mengedit maupun menghapus data berita

5. Manajemen video gallery

Pada halaman manajeme video gallery merupakan layanan untuk administrator dalam mengelola video-video yang bersumber dari youtube untuk disajkan dalam website portal ekowisata pulau Maitara

6. Manajemen foto gallery

Foto gallery merupakan layanan untuk administrator dalam mengelola foto-foto dalam mempromosikan wisata maupun kegiatan yang dapat diakses melalui halaman portal ekowisata

7. Manajemen data kuliner

Layanan manajemen kuliner berfungsi untuk administrator dalam mengelola data maupun 
informasi kuliner yang di informasikan melalui website ekowisata pulau Maitara

8. Manajemen data event

Layanan data event untuk administrator dalam mengelola informasi event yang ada di pulau Maitara

9. Manajemen peta

Layanan manajemen peta, berfungsi untuk manajemen tempat dan lokasi dalam sebuah event yang dapat dikelola oleh user administrator

10. Statistik konten,

Layanan statistic konten berisikan layanan website yang dapat dimanfaatkan oleh administrator untuk memonitoring jumlah viewer konten yang disajikan dalam website portal ekowisata pulau maitara

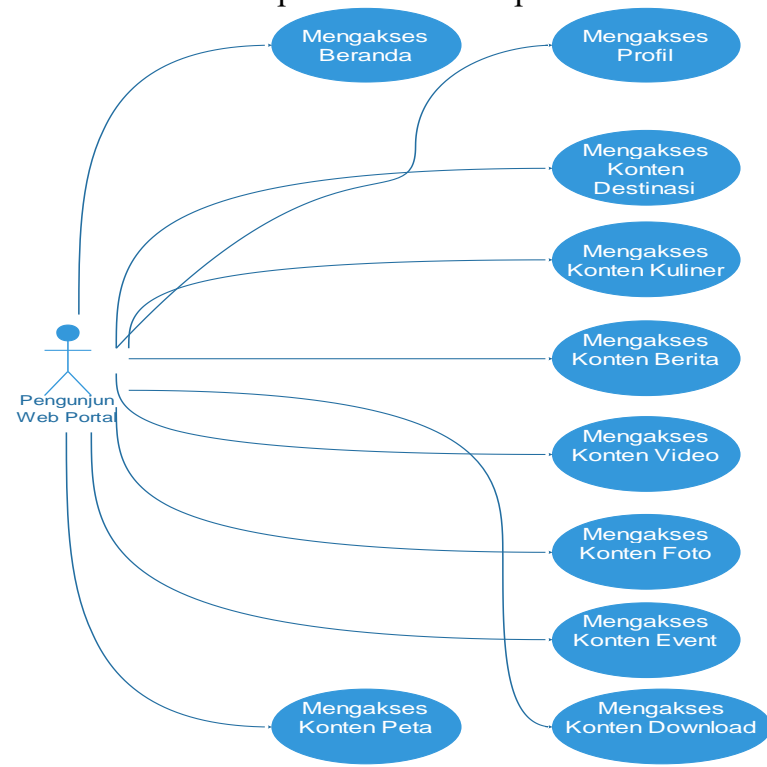

Gambar 3. use case diagram pengunjung web portal

Layanan website portal ekowisata pulau Maitara menyajikan berbagai macam informasi seputar ekowisata di pulau Maitara yang dapat diakses oleh pengunjung website yaitu :

1. Halaman beranda

2. Halaman profil

3. Halaman destinasi

4. Halaman kuliner

5. Halaman berita

6. Halaman video

7. Halaman event

8. Halaman download

9. Halaman peta

1. Perancangan Database

Database dirancang terdiri dari 1 database yang berisi 12 tabel seperti pada Gambar 3
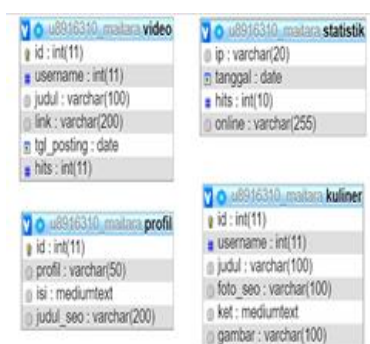

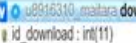

id downhad: int(11)

ojod: varcha (100)

7. to josting: date

is usenane : inti1)

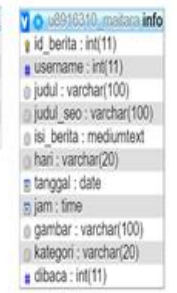

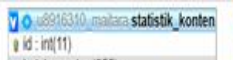

ild: int(11)

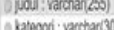

kregon: : vactur 300

aloaca : int(11)

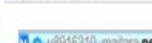

id : inti1)

id: :rtili)

o desivicsi : mediumiat

garibar : varchar(100)

o lat: varchar $(50)$

ing: varchar $(50)$

ing : varchar 50 )

पo voskesto macra slider

id in:(11)

insemane : int(11)

o jodi: : varchar $(100)$

foto seo: vachar (100)

ket:medirntex

ganbar: varchar(100)

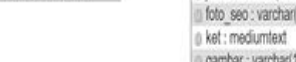

ogarbar: vardar (10

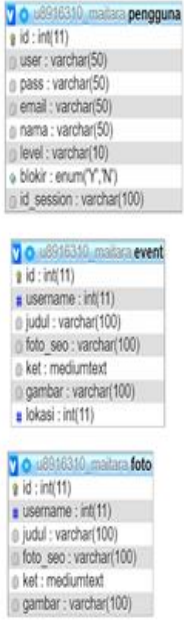

Gambar 4, perancangan database

Dalam perancangan aplikasi website portal ekowisata pulau Maitara terdapat 1 database yang terdiri dari 12 tabel, yaitu :

1. Tabel pengguna, yaitu tabel yang berisikan data user administrator dari website portal

2. Tabel info yaitu tabel yang berisikan data berita yang disajikan dalam website

3. Tabel slider, yaitu tabel yang menyimpan informasi gambar slider yang tampil pada halaman beranda website portal

4. Tabel peta, yaitu tabel yang berisikan datadata peta dari event yang ada pada halaman website portal

5. Tabel profil, yaitu tabel yang berisikan data profil pulau Maitara

6. Tabel video, yaitu tabel yang berisikan data video ekowisata

7. Tabel kuliner, yaitu tabel yang berisikan datadata kuliner khas pulau Maitara

8. Tabel event, yaitu tabel yang berisikan data event yang diselenggarakan pada pulau Maitara

9. Tabel download, yaitu tabel yang menyimpan data atau file yang dapat diakses oleh masyarakat

10. Tabel foto, yaitu tabel yang berisikan data foto-foto kegiatan ekowisata pulau Maitara

11. Tabel statistic konten, yaitu tabel yang berisikan informasi viewer konten website portal yang telah diakses oleh pengunjung website

12. Tabel statistik, yaitu tabel yang berisikan data statistik pengunjung website

C. Implementasi Sistem

Dalam impelemntasi aplikasi website portal ekowisata pulau Maitara disajikan menjadi 2 halaman 
utama yaitu halaman front end (halaman depan) yang didapat di akses oleh pengunjung website secara public sebagaimana ditunjukkan pada Gambar 5. Sementara halaman backend (halaman administrator) merupakan halaman website yang hanya dapat diakses oleh administrator website dengan terlebih dahulu melakukan autentikasi user melalui halaman login website sebagaimana ditunjukkan pada Gambar 6.

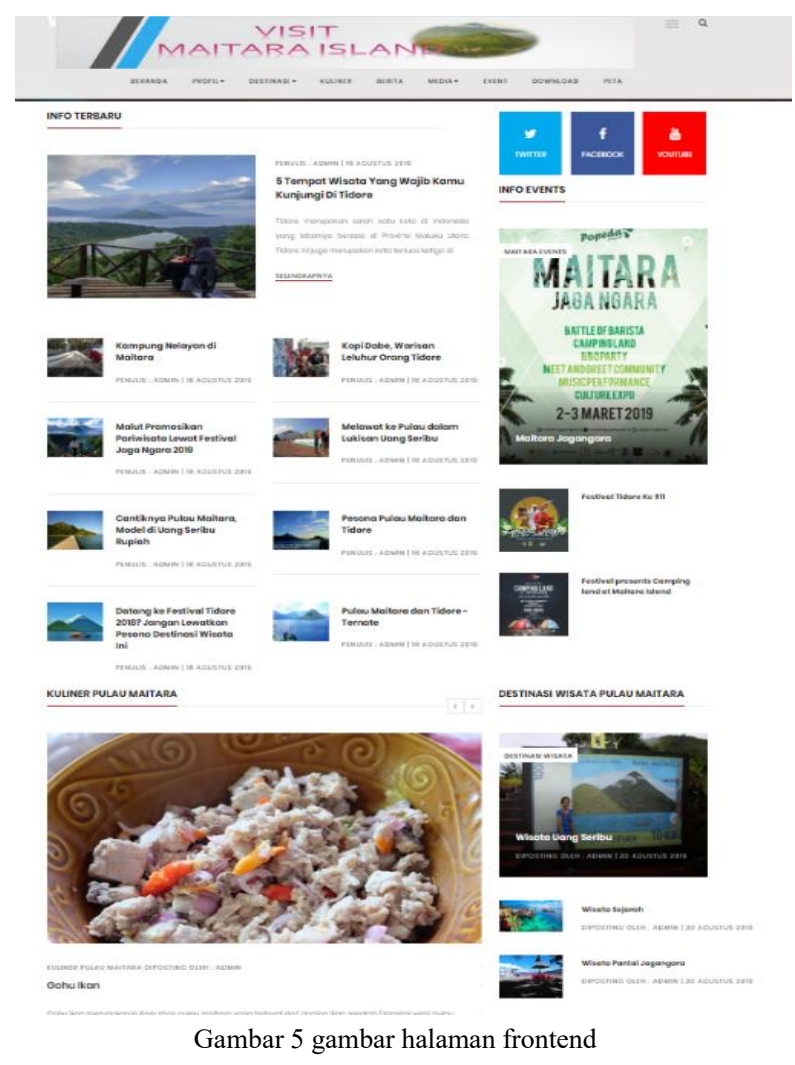

Untuk halaman administrator (back end) dapat dilihat pada Gambar 6

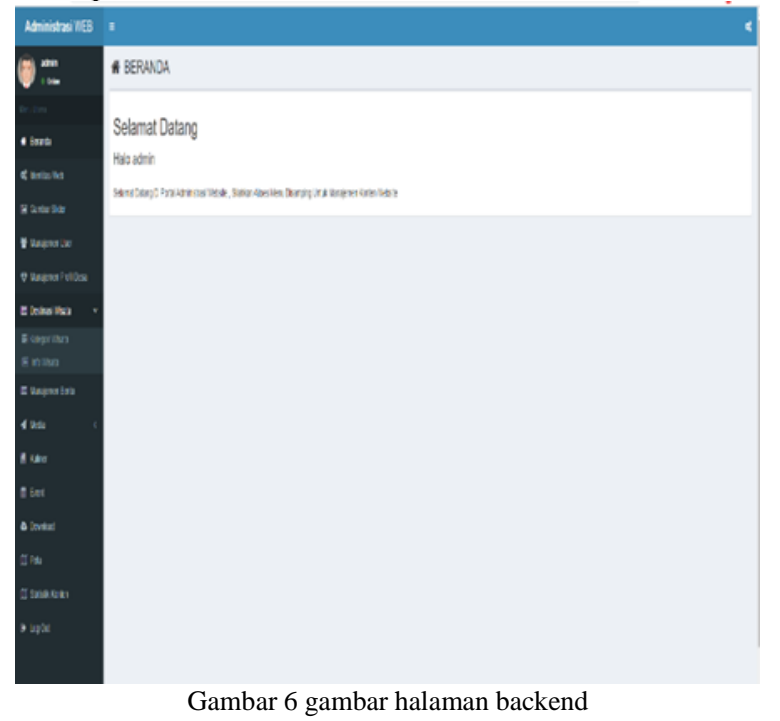

\section{Pengujian Sistem}

Pada tahapan pengujian sistem dilakukan dengan menguji fitur-fitur layanan dalam website portal menggunakan metode pengujian blackbox, pengujian blackbox yaitu pengujian dengan menguji fungsi dari sebuah aplikasi dan hasil dari pengujian seluruh fitur aplikasi webste portal telah berjalan dengan baik dapat diakses scara online melalui domain http://visitmaitaraisland.com/

\section{E. Analisis Sistem}

Aplikasi website telah dirancang menggunakan metode rekayasa perangkat lunak waterfall telah berhasil melalui tahap requirement, perancangan, implementasi, serta pengujian dengan baik tanpa adanya kendala berarti, tahap akhir dari metode waterfall adalah tahap maintenance sehingga diperlukan analisa dari sistem yang ada agar apabila terdapat kekurangan dapat dikembangkan lebih lanjut.

Pada tahap Analisa ini Penulis membagi kedalam 2 bagian, yaitu kelebihan dari aplikasi website portal ekowisata yang telah dibuat dan kelemahan atau kekurangan yang Penulis temukan dari aplikasi yang dibangun

\section{Kelebihan Aplikasi Ekowisata Pulau Maitara}

Telah banyak aplikasi website portal ekowisata sejenis yang telah dibuat oleh Peneliti lainnya salah satunya penelitian yang dilakukan oleh Edo Arribe ditahun 2018 yaitu selain menampilkan informasi wisata pada website portal juga memanfaatkan Map API google untuk menampilkan peta pada website ekowisata yang dibangun agar memudahkan user atau pengunjung dalam mengakses website ekowisata.

Pada aplikasi yang Penulis rancang serta implementasi pada penelitian ini selain menampilkan informasi ekowisata baik terkait informasi pariwisata, informasi kuliner serta beberapa fasilitas lain termasuk penggunaan google Map API, terdapat pula fitur aplikasi berupa analisis konten yang penulis rancang pada halaman administrator yang menjadi kelebihan yang menonjol pada aplikasi web portal ekowisata pulau Maitara.

Fitur analisis konten menampilkan data statistik konten viewer pada halaman administrator, fitur ini diharapkan dapat membantu administrator website dalam menyajikan konten berdasarkan minat pengunjung sehingga konten yang ditampilkan dapat lebih efektif.

2. Kelemahan Aplikasi Ekowisata Pulau Maitara

Selain kelebihan aplikasi website portal dari fitur analisis konten pada aplikasi website portal pulau Maitara yang telah dirancang dan di implementasikan, dari pengamatan serta analisis yang Penulis lakukan, Penulis menganggap penting untuk dikembangkan fitur analisis konten pada aplikasi portal ini dengan menggunakan pendekatan algoritma data mining ataupun algoritma sistem penunjang keputusan sehingga hasil analisis konten yang ditampilkan dapat lebih efektif lagi 
sesuai dengan karakteristik pengunjung pada website portal ekowisata pulau Maitara.

\section{KESIMPULAN}

Sistem website portal ekowisata telah dirancang dan diimplementasikan menggunakan metode waterfall melalui 5 tahap, dan dilakukan pengujian fungsi dengan menggunakan metode blackbox telah berjalan dengan baik, sehingga website web portal ekowisata pulau Maitara telah dapat diakses secara online melalui domain http://visit-maitaraisland.com/

Fitur unggulan pada aplikasi website portal pulau Maitara ini adalah fitur analisis konten yang dapat diakses melalui halaman administrator, sehingga dengan adanya fitur ini dapat dimanfaatkan untuk memonitoring semua konten website berdasarkan minat dari pengunjung

\section{DAFTAR PUSTAKA}

[1] A. M. Syamsul., 2017, "Resistensi Masyarakat Kelurahan Kalaodi Terhadap Program Pembangunan Unit Air Baku Rum Dan Pulau Maitara". thesis, Universitas Muhammadiyah Malang.

[2] H. Haerani., 2012, "Pembangunan Kawasan Ekowisata Di Pulau Maitara Kota Tidore Kepulauan”, Jurnal Plano Madani, vol 2(1).pp. 44-50

[3] K, E. Taghulihi., dkk., 2019, "Pengembangan Ekowisata Sebagai Sektor Unggulan Kota Manado (Studi Kasus Obyek Wisata Bunaken)", Jurnal Berkala Ilmiah. Vol 2(2). pp 7-12

[4] N. Nuraini., 2019, "Mekanisme Akses Berbasis Struktural Dan Relasional Dalam Memperkuat Kinerja Institusi Pengelolaan Ekowisata Bahari (Kasus: Kampung Wisata Arborek, Distrik Meos Mansar, Kabupaten Raja Ampat, Provinsi Papua Barat)", Tesis Pascasarjana Institut Pertanian Bogor

[5] E. Arribe., 2018. "Aplikasi Smart Tourism Pada Dinas Pariwisata Kabupaten Kampar Guna Mempromosikan Destinasi Ekowisata Kabupaten Kampar"., Jurnal Teknologi Dan Open Source, vol 4(2), pp.19-26

[6] A. J. Mustafa., A. Mubarak dan R. Rosihan., 2018. "Sistem Informasi Geografis pencarian Lokasi Bank dan ATM di Kota Ternate"., JIKO (Jurnal Informatika dan Komputer), vol. 1 (2), pp.48-55

[7] F. M. Kodja., A. Khairan dan S. Lutfi., 2018. "Sistem Informasi Geografis Pemetaan Daerah Rawan Malaria Di Kota Ternate Berbasis Web"., JIKO (Jurnal Informatika dan Komputer), vol. 1 (2), pp.92-98
[8] A. R. Laisouw., S. Lutfi dan F. Tempola., 2019. "Sistem Pendukung Keputusan Pemberian Bantuan Program Keluarga Harapan pada Orang Miskin di Kota Ternate Menggunakan Metode AHP”, JIKO (Jurnal Informatika dan Komputer), vol. 2 (1), pp.34-40

[9] A. Mubarak., 2019. 'Rancang Bangun Aplikasi WEB Sekolah Menggunakan UML (Unified Modeling Language) dan Bahasa Pemograman PHP (PHP Hypertext Preprocessor) Berorientasi Objek'. JIKO (Jurnal Informatika dan Komputer), vol. 2 (1), pp.19-25

[10] Hutabarat, Fridzy Vioretti, 2016, 'Portal Komunitas Pecinta Tanaman Hias Berbasis web Menggunakan Php Dan Mysql', Skripsi Universitas Sumatera Utara 